\title{
Pembuatan Penyaring Air Untuk Peternak Ayam Petelur di Dusun I Kubu Cubadak Simpang Petai
}

\author{
Anhar, Nurhalim, Feri Candra, Antonius Rajagukguk, Eddy Hamdani \\ Fakultas Teknik,Universitas Riau \\ Kampus Bina Widya Km 12,5 \\ email: anhar@lecturer.unri.ac.id
}

\begin{abstract}
In order to supply the water for laying hens farm in Kubu Cubadak Simpang Petai, the service team from University of Riau has designed a water purification system using the filtration technique. Before designing the filtration, sample of water from the well around the farm is taken and analyzed in the laboratory. Based on this result, the filtration is characterized to get the water satisfying the needs of the farm. There are two tubs in the filtration system containing silica sand, zeolite, and active carbon. Water from the well is pumped to the tank with three-meter height. From there, water is pumped back again to the tube to get the optimal water flow. The quality of water from the filtration have enhancement in terms of color, turbidity, and $\mathrm{pH}$. The color and turbidity of water are improved from 41 NTU to 0 NTU and from 22,5 NTU to 5,59 NTU, respectively. Furthermore, there is an increasing in $\mathrm{pH}$ of water, from 5,44 to 6,32. These results have fulfilled the standard for laying hens farm.
\end{abstract}

Keywords: water purification, filtration, color, turbidity

\begin{abstract}
Abstrak
Untuk memberikan ketersediaan air bagi peternakan ayam petelur di Kubu Cubadak Simpang Petai, tim pengabdian dari Universitas Riau telah merancang sistem pembersih air dengan teknik filtrasi. Sebelum merancang sistem filtrasi, sampel air dari sumur di sekitar peternakan diambil dan dianalisa di laboratorium. Berdasarkan hasil ini, sistem filtrasi dikarakterisasi untuk mendapatkan air yang memenuhi keperluan bagi peternakan. Ada 2 tube yang digunakan dan berisi pasir silika, zeolit, dan karbon aktif. Air dari sumur dipompa ke tangki yang tingginya 3 meter. Dari sana, water dipompa kembali ke tube untuk mendapatkan laju debit air yang optimal. Kualitas air dari filtrasi mengalami perbaikan dalam hal warna, kekeruhan, dan pH. Warna dan kekeruhan air berkurang dari 41 NTU ke 0 NTU dan dari 22,5 NTU ke 5,59 NTU. Kemudian, pH air juga meningkat, dari 5,44 menjadi 6,32. Hasil ini telah memenuhi standar air bagi peternakan ayam petelur.
\end{abstract}

Kata Kunci: pembersih air, teknik penyaringan, warna, kekeruhan

\section{PENDAHULUAN}

\section{Analisis Situasi}

Dusun I Kubu Cubadak merupakan salah satu desa yang ada di desa Simpang Petai Kecamatan Rumbio Jaya Kabupaten Kampar. Desa simpang petai sendiri memiliki penduduk sejumlah 1374 jiwa pada tahun 2018[1]. Sedangkan Dusun I Kubu Cubadak berpenduduk 270 jiwa[1]. Desa Simpang Petai berjarak 20,4 Km dari ibukota kabupaten dan dapat ditempuh melalui jalur darat selama 37 menit. Desa ini di bagian selatan berbatasan langsung dengan sungai kampar yang memiliki panjang 441 meter, salah satu sungai terbesar di provinsi Riau.

Dari luas lahan sebesar 3009 ha, lahan sebesar 348 ha digunakan untuk lahan perkebunan, 70 ha digunakan untuk pertanian, dan sisanya dimanfaatkan untuk lainnya seperti perumahan, jalan, kantor pemerintahan dan kantor swasta, serta 
fasilitas atau gedung lainnya. Dari kondisi pemanfaatan lahan tersebut terlihat bahwa umumnya masyarakat di desa ini bekerja sebagai petani kebun dan sawah.

Selain perkebunan dan pertanian, masyarakat di desa simpang petai khususnya dusun I Kubu Cubadak membuat peternakan ayam petelur sebagai usaha untuk memenuhi kebutuhan lokal dan masyarakat sekitar dusun. Peternakan ayam yang dibangun mendapatkan bantuan modal dari dana desa yang disalurkan ke dusun I. Di dusun I, ada 2 peternakan ayam yang masih produktif hingga saat ini. Peternakan ini memberikan kontribusi yang cukup besar bagi pendapatan warga.

Seperti usaha peternakan pada umumnya, ketersedian air bagi peternakan ayam petelur sangat penting karena air merupakan komponen penyusun terbesar tubuh ayam berkisar 60-85\%[2]. Kekurangan air bagi hewan ternak sebanyak $20 \%$ dapat menyebabkan kematian[3].

Usaha peternakan ayam petelur di dusun I Kubu Cubadak memanfaatkan air sumur warga yang ada di sekitar peternakan untuk menyuplai kebutuhan tersebut. Namun, kualitas air sumur tersebut tidak baik dan ketersediaanya pun terbatas karena tidak memiliki media penampungan. Sehingga, hal ini menimbulkan kesulitan dalam menyediakan air minum untuk ayam petelur tersebut secara terus menerus. Untuk mengatasi permasalahan tersebut, maka tim pengabdian masyarakat Universitas Riau membuat alat penyaring air bersih untuk peternakan tersebut. Diharapkan dengan dikembangkannya alat ini dapat meningkatkan produktifitas peternakan telur di dusun I Kubu Cubadak.

\section{Tinjauan Pustaka}

Air merupakan salah satu komponen penting dalam kehidupan mahluk hidup. Air bersih, salah satu jenis air, banyak dibutuhkan oleh mahluk hidup dikarenakan air ini memiliki karakteristik yang dapat digunakan untuk komsumsi dan kebutuhan lainnya. Air bersih dikarakteristikkan dengan[4][5]:

1. Jernih, tidak berbau dan tidak berasa.

2. Suhunya sejuk dan tidak panas.

3. Bebas dari unsur-unsur kimia berbahaya.

4. Tidak mengandung unsur mikrobiologi yang berbahaya.

Sedangkan dalam peraturan pemerintah nomer 20 tahun 1990 tentang pengendalian pencemaran air disebutkan bahwa kualitas air dipengaruhi beberapa parameter, yaitu parameter fisika, kimia, dan radioaktif. Selanjutnya, pada pasal 7 , air digolongkan berdasarkan peruntukannya sebagai berikut [6]:

1. Golongan A: air untuk air minum tanpa pengolahan

2. Golongan B: air baku air minum

3. Golongan $\mathrm{C}$ : air untuk perikanan dan peternakan

4. Golongan D: air untuk pertanian dan usaha.

Untuk mendapatkan air dengan kualitas atau peruntukan tertentu, dilakukan teknik pengolaan air. Secara umum, teknik pengolahan air dikelompokkan menjadi[4][7]:

1. Teknik koagulasi, yaitu teknik pengolahan air yang diterapkan dengan bantuan koagulan kimia seperti Polyelektrolit (misalnya: PAC atau Poly Aluminium Chloride, PAS atau Poly Aluminium Sulfat), garam aluminat (misalnya: alum, tawas), garam Fe, khitin, dan sebagainya.

2. Teknik redoks yaitu teknik pengolahan air yang diterapkan dengan bantuan inhibitor seperti senyawa khlor (misalnya: kaporit), non khlor atau teknik redoks lainnya.

3. Bioremoval dan Bioremidiasi merupakan teknik pengolahan air 
dengan menggunakan biomaterial. Biomaterial tersebut antara lain lumut, daun teh, sekam padi, dan sabut kelapa sawit, atau juga dari bahan non biomaterial seperti perlit, tanah gambut, lumpur aktif dan lain-lain.

4. Reverse osmosis yaitu teknik pengolahan air yang merupakan kebalikan dari proses osmosis alami. Osmosis adalah perpindahan cairan dari konsentrasi rendah ke konsentrasi tinggi yang melewati membran semipermeabel.

5. Teknik filtrasi atau penyaringan yaitu teknik pengolahan air yang diterapkan dengan bantuan media filter seperti pasir (misalnya: silika, antrasit), senyawa kimia atau mineral (misalnya: kapur, zeolit, karbon aktif, resin, ion exchange), membran, biofilter atau teknik filtrasi lainnya.

Diantara kelima metode tersebut, teknik filtrasi yang banyak digunakan untuk mendapatkan kualitas air bersih yang sederhana. Teknik filtrasi memisahkan solid-liquid dengan cara melewati liquid melalui media berpori untuk menyisihkan atau menghilangkan butiran-butiran halus zat padat tersuspensi dari liquid[8]. Proses ini merupakan cara yang cukup efektif untuk menghilangkan kekeruhan, warna, bakteri, dan logam seperti besi[9].

Ada beberapa material atau media berpori yang umum digunakan pada proses filtrasi, diantaranya adalah[9][10][11]:

1. Pasir silika adalah medium yang berfungsi untuk menyaring padatan yang ada di dalam air serta oksida besi atau oksida mangan. Pasir silika sangat efektif untuk menyaring lumpur dan bahan pengotor air.

2. Zeolit merupakan senyawa aluminosilikat berhidrat dengan kation natrium, kalium dan barium. Fungsi utama medium ini adalah untuk membasmi bakteri dan mengikat kandungan logam di dalam air.

3. Karbon aktif bermanfaat untuk menghilangkan warna. Selain itu, medium ini dapat menyerap polutan mikro yang ada di dalam air dan menghilangkan bau.

\section{METODE PENGABDIAN}

Pada kegiatan pengabdian ini, alat, bahan atau material yang digunakan adalah:

1. Pasir silika

2. Karbon aktif

3. Zeolit

4. Pipa PVC $3 / 4$

5. Tangki air kapasitas 500liter

6. Pompa air

7. Tabung 1024

\section{Kabel NYM}

Untuk mencapai tujuan dari pengabdian ini, maka disusun beberapa metode atau tahapan, yang rinciannya adalah sebagai berikut:

1. Survei lokasi dan pengambilan sampel air. Sampel yang sebanyak $600 \mathrm{ml}$ diambil dari sumur yang digunakan untuk memberi minum peternakan ayam tersebut, dan kemudian dianalisa di laboratorium kesehatan, Dinas Kesehatan Kota Pekanbaru.

2. Pembuatan tower sebagai dudukan tangki air. Tower dirancang dengan tinggi $3 \mathrm{~m}$ sehingga didapatkan debet air yang cukup. Tower yang digunakan dapat dilihat pada gambar 1 . 


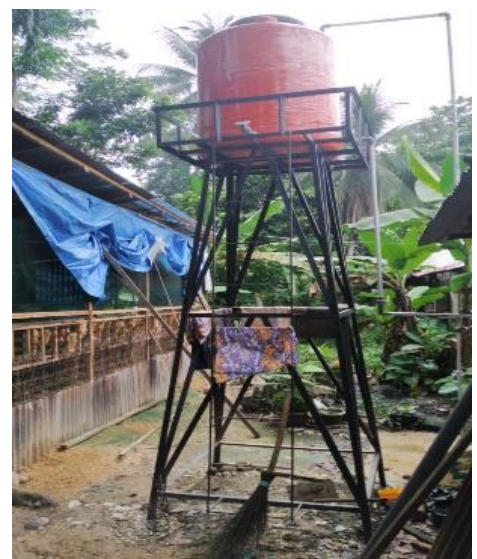

Gambar 1. Tower penopang tangki

3. Pembuatan filtrasi dengan menggunakan pasir silika, zeolit, dan karbon aktif. Teknik filtrasi ini menggunakan sistem dua tabung, dimana teknik filtrasi pertama menggunakan pasir silika. Sedangkan filtrasi kedua menggunakan material kombinasi zeolit dan karbon aktif. Susunan rancangan sistem penyaring air bersih 2 tabung diperlihatkan pada gambar 2 .

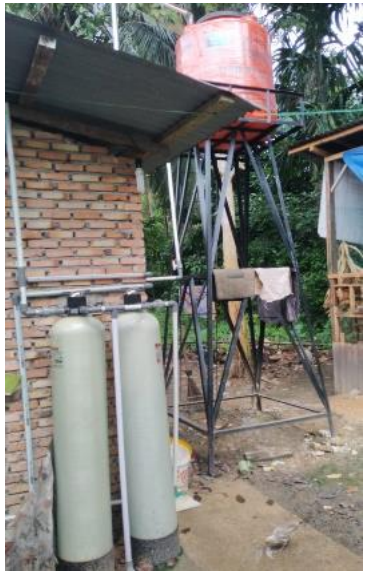

Gambar 2. Sistem Penyaring 2 Tabung

4. Instalasi perangkat di lokasi peternak ayam petelur.

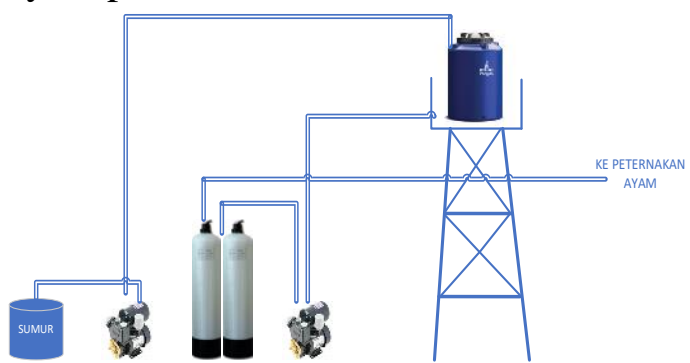

Gambar 3. Arsitektur Sistem Penyaring
5. Pengujian hasil filtrasi air bersih di laboratorium kesehatan, Dinas Kesehatan Kota Pekanbaru.

Tahapan tersebut dapat digambarkan dalam flow chart diagram seperti ditunjukkan pada gambar.

\section{HASIL DAN PEMBAHASAN}

Seperti diuraikan pada metode pengabdian bahwa tahapan awal sebelum melakukan desain alat penjernih air bersih, sampel air yang digunakan untuk mensuplai air minum untuk peternakan tersebut diuji di laboratorium kesehatan Kota Pekanbaru. Beberapa parameter hasil uji tersebut ditunjukkan pada tabel 1 berikut.

Tabel 1. Hasil uji air sebelum filtrasi.

\begin{tabular}{|l|l|l|l|}
\hline No. & Parameter & Satuan & $\begin{array}{c}\text { Hasil } \\
\text { Pemeriksaan }\end{array}$ \\
\hline 1 & Bau & - & Tdk berbau \\
\hline 2 & Kekeruhan & NTU & 22,5 \\
\hline 3 & Rasa & - & Tdk berasa \\
\hline 4 & Warna & NTU & 41 \\
\hline 5 & Besi & $\mathrm{mg} / 1$ & 0,68 \\
\hline 6 & pH & $\mathrm{mg} / 1$ & 5,44 \\
\hline
\end{tabular}

Dari tabel 1 tersebut terlihat bahwa tingkat kekeruhan dan warna air cukup tinggi, yaitu 22,5 NTU, dan 41 NTU. Selain itu, jumlah zat besi yang terdapat pada air dan $\mathrm{pH}$, yaitu $0,68 \mathrm{mg} / \mathrm{l}$ dan 5,44 $\mathrm{mg} / \mathrm{l}$. Dengan karakteristik air seperti ini, disusunlah sistem penyaring dua tabung untuk mendapatkan tingkat kekeruhan yang lebih baik. Selain itu, parameter lain seperti $\mathrm{pH}$, jumlah zat padat terlarut serta bakteri kaliform juga diperhatikan.

Setelah sistem penyaringan dibuat dan dikarakterisasi, hasil uji air tersebut dapat dilihat pada tabel 2. Sedangkan gambar 4 memperlihatkan komprasasi nilai tersebut dalam grafik batang.

Tabel 2. Hasil uji air setelah filtrasi.

\begin{tabular}{|l|l|l|l|}
\hline No. & Parameter & Satuan & $\begin{array}{c}\text { Hasil } \\
\text { Pemeriksaan }\end{array}$ \\
\hline 1 & Bau & - & Tdk berbau \\
\hline 2 & Kekeruhan & NTU & 5,59 \\
\hline 3 & Rasa & - & Tdk berasa \\
\hline
\end{tabular}




\begin{tabular}{|l|l|l|l|}
\hline No. & Parameter & Satuan & $\begin{array}{c}\text { Hasil } \\
\text { Pemeriksaan }\end{array}$ \\
\hline 4 & Warna & NTU & 0 \\
\hline 5 & Besi & $\mathrm{mg} / \mathrm{l}$ & 0,15 \\
\hline 6 & $\mathrm{pH}$ & $\mathrm{mg} / \mathrm{l}$ & 6,32 \\
\hline
\end{tabular}

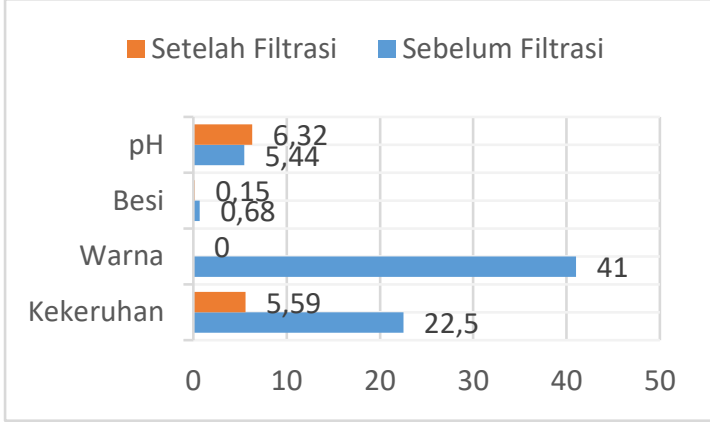

Gambar 4. Perbandingan hasil uji air sebelum dan sesudah dilakukan analisa laboratorium.

Gambar 4 memperlihatkan perbandingan kualitas air pada sebelum dan sesudah analisa laboratorium. Dua parameter yang cukup besar perubahannya adalah warna dan kekeruhan. Tingkat perubahan warna dari 41 NTU menjadi 0 . Sedangkan kekeurahan dari skala 22,5 NTU menjadi 5,59. Ini menunjukkan bahwa sistem penyaringan 2 tabung yang terdiri dari material pasir silika, karbon aktif, dan zeolit sangat efektif memperbaiki mutu air dalam 2 aspek tersebut. Sementara itu, $\mathrm{pH}$ air mengalami sedikit perbaikan dari skala rendah 5,44 menjadi 6,32. Hasil ini sudah dipandang cukup memadai untuk kualitas air bersih bagi peternakan ayam petelur.

\section{SIMPULAN}

Sistem penyaring 2 tabung yang menggunakan material pasir silika, karbon aktif, dan zeolit telah dirancang untuk memperbaiki kualitas air di dusun $1 \mathrm{Kubu}$ Cubadak Desa Simpang Petai yang diperuntukkan bagi usaha peternakan ayam petelur. Terjadi perbaikan kualitas air yang cukup signifikan yaitu pada parameter kekeruhan dan warna. Hasil analisa laboratorium menunjukkan kualitas air telah memadai untuk usaha peternakan itu.

\section{UCAPAN TERIMAKASIH}

Penulis mengucapkan terima kasih kepada Lembaga Penelitian dan Pengabdian kepada Masyarakat (LPPM) Universitas Riau yang telah mendanai kegiatan pengabdian ini.

\section{DAFTAR PUSTAKA}

[1] Badan Pusat Statistik Provinsi Riau, "Jumlah Penduduk berdasarkan Jenis Kelamin Menurut Kabupaten/Kota di Provinsi Riau 2010-2019," 2020. https://riau.bps.go.id/dynamictable/ 2019/10/22/78/jumlah-pendudukberdasarkan-jenis-kelaminmenurut-kabupaten-kota-diprovinsi-riau-2010-2018.html (accessed Nov. 07, 2020).

[2] "Optimal Menjaga Kualitas Air Peternakan," 2019. https://www.medion.co.id/id/optim al-menjaga-kualitas-air-dipeternakan/ (accessed Sep. 18, 2020).

[3] D. P. Liptan, "Manfaat Air Minum," no. 0274, 1997.

[4] B. Wicaksono, D. Mayasari, P. S. P, T. Iduwin, and T. Yuhanah, "Edukasi Alat Penjernih Air Sederhana Sebagai Upaya Pemenuhan Kebutuhan Air Bersih," Terang J. Pengabdi. pada Masy. Menerangi Negeri, vol. 2, no. 1, pp. 43-52, 2019.

[5] S. Purwoto and J. Sutrisno, "Pengolahan Air Tanah Berbasis Treatment Ferrolite, Manganese Zeolite, Dan Ion Exchange," J. Tek. Waktu, vol. 14, no. 2, pp. 21-31, 2016.

[6] P. R. Indonesia, PP No. 20 Thn 1990 tentang Pendendalian Pencemaran Air. Indonesia, 1999.

[7] M. Suarda and D. I Wayan, "Perencanaan Penyaring Air 
Sederhana Untuk Sistem Air Bersih Pedesaan," 2010.

[8] S. Widyastuti and A. S. Sari, "Kinerja Pengolahan Air Bersih

Dengan Proses Filtrasi Dalam Mereduksi Kesadahan," J. Tek. Waktu, vol. 09, no. 01, pp. 42-53, 2011.

[9] A. Mugiyantoro, I. Husna Rekinagara, C. Dian Primaristi, and J. Soesilo, "Penggunaan Bahan Alam Zeolit, Pasir Silika, Dan Arang Aktif Dengan Kombinasi Teknik Shower Dalam Filterisasi Fe, Mn, Dan Mg Pada Air Tanah Di Upn 'Veteran' Yogyakarta," in Seminar Nasional Kebumian ke-10, 2017, no. 492, pp. 1127-1137.

[10] R. Coenraad, Wiratno, and Karelius, "Perancangan Filter Penjernih Air Sungai Kahayan Berbasis Pasir Silika Dan Lempung Alam Asal Kalimantan Tengah," J. Jejaring Mat. dan Sains, vol. 1, no. 2, pp. 70-76, 2019, doi: 10.36873/jjms.v1i2.213.

[11] K. Pengkajian Sistem Pengolahan Air, "Cara Pengolahan Air Sumur Untuk Kebutuhan Air Minum," Pos Pelayanan Informasi Teknologi. 